\title{
An experimental study on DC-CIK cells' immuno effects on killing gastric cancer cells in vitro.
}

\author{
Hou-Jun Cao', Ti-Ye Sun ${ }^{2}$, Wei Yan $^{3}$, Chun-Min Yang ${ }^{3}$, Long-Fang Zhang ${ }^{3}$, Ying Jin ${ }^{3}$, Jie Qiu ${ }^{3}$, Hai- \\ Xiang $\mathrm{Hu}^{3}$, Xuan $\mathrm{Wei}^{3}$ \\ ${ }^{1}$ General Surgery, Air Force General Hospital, Beijing, PR China \\ ${ }^{2}$ Department of Urology, Air Force General Hospital, Beijing, PR China \\ ${ }^{3}$ Department of Gerontology, General Hospital of the Air Force, Beijing, PR China
}

\begin{abstract}
Objective: To investigate the anti-gastric cancer immuno effects of DC-CIKs against gastric cancer cells by co-culturing Dendritic Cells (DCs) with Cytokine-Induced Killer cells (CIKs) derived from peripheral blood mononuclear cells of patients with gastric carcinoma.

Methods: Collecting $30 \mathrm{ml}$ peripheral blood of patient of gastric cancer, we separate peripheral blood with lymphocyte separation liquid to obtain mononuclear cells respectively, and used for generating DC with the treatment of recombinant human Granulocyte Macrophage Coliny Stimulating Factor (rhGMCSF) and recombinant human Interleukin-4 (rhIL-4) as well producing CIK with interferon- $\gamma($ IFN- $\gamma$ ), CD3 and rhIL-2 in vitro, mixing SGC-7901 cells of DC and CIK cells and then DC and CIK were cocultured according to the ratio of 1:10 to produce DC-CIK. The experiment was performed with three groups composed of DC-CIK group, DC group and CIK group. After $14 \mathrm{~d}$ of co-culture, increased number of cells were counted by trypan blue staining, cytotoxic activity against SGC-7901 cells in three groups were detected by MTT assay. The Flow Cytometry (FCM) was used to measure the antigen expression of the $\mathrm{CD}_{1 \mathrm{a}}, \mathrm{CD}_{\mathbf{8 3}}, \mathrm{CD}_{\mathbf{8 6}}, \mathrm{CD}_{\mathbf{8 0}}, \mathrm{CD}_{40}, \mathrm{HLA}-\mathrm{DR}$ and the lymphocyte subsets of $\mathrm{CD3}+$, CD3+CD8+ and CD3+CD56+ of the three groups cells. Levels of Interleukin-12 (IL-12), Interleukin-4 (IL-4), the Interferon- $\gamma($ IFN- $\gamma$ ) and Tumor Necrosis Factor- $\alpha$ (TNF- $\alpha)$ in the supernatants of DC-CIK, DC and CIK cells culture were detected by Enzyme-Linked Immunosorbent Assay (ELISA).

Results: After culturing for $14 \mathrm{~d}$ in vitro, the proliferation capability and the cells percentage of antigen expression of peripheral blood DC-CIK cells was significantly higher than that of DC and CIK cells $(\mathbf{p}<0.01)$. The killing activity of DC-CIK cells was significantly higher than that of DC and CIK cells, with effect-target ratio increasing, the killing activity increased gradually $(\mathrm{p}=0.000)$. $\mathrm{CD3}+\mathrm{CD8}+$, CD3+CD56+ double positive cells in DC-CIK co-culture were significantly increased than that DC and CIK groups under the same conditions ( $p<0.01$ ). The concentrations of IL-12, IL-4, IFN- $\gamma$ and TNF-ain the cultural super mutant in the DC-CIK group were significantly higher than DC and CIK groups $(p=0.000)$. However, there is no statistics difference among the DC and CIK groups ( $p>0.05)$.

Conclusion: DC-CIK can induce potent immunological effect against gastric cancer cells. Immuno efficacy of DC-CIK against gastric cancer is relevant to cytokine and cytotoxicity, which provides theoretical and experimental basis for the clinical immunotherapy of gastric cancer.
\end{abstract}

Keywords: Dendritic cells, Cytokine-induced killer cells, DC-CIK cells, Cytotoxicity, Cytokine, Gastric cells, Immunotherapy.

Accepted on February 05, 2018

\section{Introduction}

Gastric cancer is one of common malignant cancer in digest. The incidence of gastric cancer was rising in recent years in China. Surgery and chemotherapy were the effective treatment means of early gastric cancer. But there was no satisfactory treatment for those patients with advanced or metastatic gastric cancer currently. Many studies show that the immune function in cancer patients was lower, and the tumor cells can evade the body's immune system to recognize through a variety of mechanisms [1]. Dendritic cells (dendritic cell, DC) was found the most functions professional antigen-presenting cells (antigen presenting cell, APC) in the body, which play an important role in the body's anti-tumor immune responses [2,3]. Cytokine-induced killer cells (cytokine-induced killer cells $(\mathrm{CIK})$ ) were acquired after co-cultured with human 
peripheral blood mononuclear cells in vitro by a variety of cytokines (such as IFN- $\gamma$, IL-2, etc.) and CD3+ monoclonal antibody, which were kinds of heterogeneous cells composed by $\mathrm{CD} 3+\mathrm{CD} 8+$ and $\mathrm{CD} 3+\mathrm{CD} 56+$ double positive cells, which were one of the most optimal cells in current tumor immunotherapy in clinical application $[4,5]$. DC can recognize antigens and activate the acquired immune system. CIK can kill tumor cells though their cytotoxicity and cytokine secretion. But when the DC cells having a strong ability of tumor antigen-presenting were co-cultured with the CIK cells having a high efficiency killing activity, both can be adjusted to each other, CIK cells can promote DC maturation, while DC cells can enhance the proliferation and cytotoxic activity of CIK cells [6]. In this study, the PBMC (Peripheral Blood Mononuclear Cell) was isolated from peripheral blood in patients with gastric cancer, and then DC, CIK and DC were co-cultured to CIK (DC-CIK), which were induced and amplification cultured in vitro. We researched the phenotype, secreted cytokine and the cytotoxic activity to gastric cancer cells of DC, CIK and DC-CIK respectively to examine the immune effects to the gastric cancer cells of DC-CIK in vitro and provide experimental evidence and theoretical basis for the DC-CIK cells against gastric cancer treatment.

\section{Materials and Methods}

\section{Reagents source}

RPMI1640 cell culture medium and fetal bovine serum were purchased from Gibco Company; anti-Per-CPCD3, anti-PECD56, anti-FITC-CD4, anti-APC-CD8, PE-CD86 mAb, FITC$\mathrm{CD} 40 \mathrm{mAb}$ were purchased from Becton Dickinson Company in United States, the determination of monoclonal antibody used in flow cytometry such as CD3, CD1a, CD83, CD80, CD86, CD40, HLA-DR, CD3CD4, CD3CD8, CD3CD56 and recombinant human interleukin-12 (rhIL-12), recombinant human leukocyte interleukin-4 (rhIL-4), recombinant human interferon- $\gamma$ (rhIFN- $\gamma$ ), a recombinant human tumor necrosis factor- $\alpha$ (rhTNF- $\alpha)$, recombinant human granulocytemacrophage colony stimulating factor (rhGM-CSF) were conducted by PeproTech Company. The ELISA kits purchased from PeproTech Company. MTT and lymphocyte separation medium (Ficoll) were purchased from Sigma company. The flow cytometry (FACS Calibur) were both purchased from BD Pharmingen Company in German.311 TE incubator of $\mathrm{CO}_{2}$ was purchased in TE companies in American, inverted microscope was produced by Olympus company in Japanese, human gastric cancer cell line SGC-7901 were supplied by the Central Laboratory in Third Military Medical University.

\section{The subculture of human gastric cancer cells SGC-7901}

The SGC-7901 cells were recovery cultured which were containing the medium with 10\% RPMI 1640. Then the recovery SGC-7901 cells were subculture placed in $37^{\circ} \mathrm{C}$ with $5 \% \quad \mathrm{CO}_{2}$ under saturated humidity conditions, after that, staining with trypan blue, counting the viable cell, and the ration of living cells was required more than $95 \%$. The cells in logarithmic growth phase were used for experiments.

\section{Cell culture}

Peripheral blood of $30 \mathrm{ml}$ was collected from the patients with gastric cancer, obtaining PBMC though density gradient centrifugation by lymphocyte separation medium (Ficoll), then made it heavy suspension in RPMI 1640 medium with $10 \%$ fetal bovine serum and the cell concentration was adjusted to 6 $\times 10^{6} / \mathrm{ml}$ and then culturing in $37.0^{\circ} \mathrm{C}$ with $5 \% \mathrm{CO}_{2}$ in the incubator for $2 \mathrm{~h}$.

(1) We obtained the adherent cells, which were cultured in complete medium with rhGM-CSF and rhIL-4 of $10 \mathrm{ng} / \mathrm{ml}$. The medium was changed once a day in half-quantity, and at the same time adding cell growth factor and at the sixth day adding $50 \mathrm{U} / \mathrm{ml}$ of rhTNF- $\alpha$ in order to induce DC maturation, when the ration of CD11cCD83 double positive cell was more than $90 \%$, the next test can conduct. Part of which was continue training by adding amplify culture solution, the DC cells were obtained after seven days' training, at this time we made cell phenotype analysis. Another part of DC cells were made induced culture adding rhIL-4 $500 \mathrm{U} / \mathrm{ml}$ and rhGM-CSF $550 \mathrm{U} / \mathrm{ml}$, at the same time added SGC-7901 cell lysate, which were co-cultured to the fourth day.

(2) Non-adherent cells were collected, the RPMI 1640 with $10 \%$ fetal calf serum was adjusting the cell concentration of 6 $\times 10^{6} / \mathrm{ml}$, which were suspension culturing adding $1000 \mathrm{U} / \mathrm{ml}$ of IFN- $\gamma$, adding $1 \mu \mathrm{g} / \mathrm{ml} \mathrm{CD3}$ monoclonal antibodies and $1000 \mathrm{U} / \mathrm{ml}$ of rhIL-2 after $24 \mathrm{~h}$, medium was changed every two days in half-quantity, which were amplified cultured at a maintained cell concentration of $1 \times 10^{6}$ cells $/ \mathrm{ml}$ by supplementing rhIL-2 and continued to train. Thereafter count every $2 \mathrm{~d}$; furthermore the CIK was induced maturation by supplementing the culture solution adding $\operatorname{rhTNF}-\alpha 50 \mathrm{U} / \mathrm{ml}$ at the sixth day. When the proportion of CD3CD56 double positive cells was more than $20 \%$, the next test can conduct. Part of which were cultured for $7 \mathrm{~d}$ adding both amplification solution and SGC-7901 cell lysate. Other part of which were used to induction culture of CIK cells, collecting CIK cells after $14 \mathrm{~d}$ and then made phenotypic analysis.

(3) DC and CIK cells were respectively viable cell counted by trypan blue obtained at the seventh day of culture and adjust cell concentration to $1 \times 10^{6} / \mathrm{ml}$, which were co-cultured with CIK cell by a ratio of $1: 10$, the culture system is still the incubation system of CIK cell, the DC-CIK cells were obtained after $14 \mathrm{~d}$ of co-culture, which were used for the detection of biological characteristics for DC-CIK cells.

\section{Grouping}

The cells were grouped into three groups according the composition of effector cell: DC and CIK were co-cultured as the DC-CIK group, DC group and CIK group. The experimental conditions in three groups maintained consistency. 


\section{The detection of cell surface antigen}

The cells were respectively prepared as suspension of $1 \times 10^{6}$ cells $/ \mathrm{ml}$ in test tube of the flow cytometry, and then centrifugation with the speed of $500 \mathrm{r} / \mathrm{min}$, abandon the supernatant and added PBS $100 \mu \mathrm{l}$, winded and percussion for mixed, and then reserved cells. Three groups were both added the same type of negative control.

According to the instructions of labelled antibody in the $\mathrm{BD}$ company in US, the CD3-PerCP, CD4-FITC, CD8-PE and CD56-APC were added to the test tube and mixed, after that incubated darkly at $4^{\circ} \mathrm{C}$ for $30 \mathrm{~min}$, the cells were washed three times with phosphate buffer (PBS), after that, they were suspended in $0.5 \mathrm{ml}$ PBS and were added FITC-labelled CD3 antibody and PE-labelled CD8, CD56 antibody, which were incubated darkly at $4^{\circ} \mathrm{C}$ for $30 \mathrm{~min}$, the expression of cell surface markers as $\mathrm{CD} 3+, \mathrm{CD} 3+\mathrm{CD} 4+, \mathrm{CD} 3+\mathrm{CD} 8+$ and $\mathrm{CD} 3+\mathrm{CD} 56+$ were detected by flow cytometry.

\section{Analysis of activity of cell killing in vitro}

The DC-CIK, DC, CIK cell having cultured for $14 \mathrm{~d}$ were selected as effector cells and the SGC-7901 cells in logarithmic growth phase were selected as target cells, the concentration was adjusted to $1 \times 10^{6} / \mathrm{mL}$, the ratio of effector cells to target cells was set as 2.5: 1, 5: 1, 10:1, 20: 1, 40: 1, placed in 96well plates. A separate group of target cells alone and effector cells alone was as a control group, each group set three wells and incubated for $8 \mathrm{~h}$ at $37^{\circ} \mathrm{C}$ with $5 \% \mathrm{CO}_{2}$, after that MTT of $10 \mu \mathrm{l}(5 \mathrm{~g} / \mathrm{l})$ was added to each well, continue incubated for 4 $\mathrm{h}$, the centrifugal supernatant was removed, each well was added $100 \mathrm{ul}$ of dimethylsulfoxide (DMSO) to terminate the reaction, shocking for dissolved particles, detect the absorbance (A value) with microtiter detector measurement at a wavelength of $570 \mathrm{~nm}$, the kill rate was calculated as follows: The killing rate $=(1-($ effector to target cell control efficiency in the experimental group A- A value)/target cell group A value) $\times 100 \%$.

\section{The detection of cytokines}

Culture supernatant 100 ul having cultured for fourteen days in the groups of DC-CIK group, DC group and CIK group were seeded in 96-well culture plate respectively, which was removed after cultured in an incubator for $24 \mathrm{~h}$, secretion of IL-12, TNF- $\alpha$, IFN- $\gamma$ and IL-4 in culture supernatants of each group were detected according with the operating requirements of IL-12, TNF- $\alpha$, IFN- $\gamma$ and IL-4 ELISA kit.

\section{Statistical methods}

Statistical software of SPSS 19.0 was applied, all the data are showed as $(\overline{\mathrm{x}} \pm \mathrm{s})$, the comparison of mean in two samples used paired t-test, and that in multiple samples used $\mathrm{x}^{2}$ analysis, test level $\mathrm{a}=0.05, \mathrm{P}<0.05$ meant that the difference was statistically significant.

\section{Results}

\section{Cell morphological observation}

(1) The mononuclear cells obtained after cultured $3 \mathrm{~h}$ in the peripheral blood had the following texture that adherent cells were small and round; After $3 \mathrm{~d}$ cultured, the cells gradually became irregular in shape, tiny dendritic protrusions appeared in the surface; At the $5^{\text {th }} \mathrm{d}$, volume became more larger, and the burr-like protrusions increased in the surface, some cells were initially suspended, which gathered into a cell groups of varying sizes and showed a typical of DC morphology.

(2) CIK cells cultured for three days were observed under inverted microscope that the number of cells increased and the volume some became larger, at the $6^{\text {th }} \mathrm{d}$ the speed of growth was found significantly faster and grew in in clusters and colony mode.

(3) DC and CIK were observed under a microscope after cocultured.

That the proliferation of CIK cells were significantly faster, a large number of which were round, and the surround was shiny, the number increased significantly, while the number of irregular cells also significantly increased, suspension cells showed a significant cluster-like growth. cell count displayed by trypan blue viable that the number of DC-CIK cells were amplified to $96.38 \pm 6.51 \%$, the number of DC cell were expanded to $68.86 \pm 6.57 \%$, and that was expanded to $66.39 \pm$ $6.64 \%$ on CIK cells, the number was respectively as thirteen times, six times, and eight times as the original one. The amplification times of cells compared in DC-CIK group and DC, CIK group, the difference was significant statistical significance $(p<0.01)$.

\section{The detection of cell surface antigen}

The results detected by flow cytometry indicated that adherent cells in the peripheral blood of gastric cancer patients can be cultured mature DC, while non-adherent cells can be cultured mature CIK.

DC-CIK, DC and CIK cells were respectively cultured for 14 $\mathrm{d}$, at this time the cell suspension were collected by flow cytometry, and the results showed that the expression of cell surface markers all showed high expression, and the rate of surface antigen markers on DC-CIK cell was significantly increased than that on DC and CIK cells ( $p<0.01$, Table 1).

We found that the cells in three groups all showed high expression of $\mathrm{CD} 3+$ by detecting cell surface phenotype in three groups and the difference was significant statistical significance $(p<0.01)$.

With the increasing of incubation time, the expression of double positive cells $\mathrm{CD} 3+\mathrm{CD} 4+, \mathrm{CD} 3+\mathrm{CD} 8+$ ratio for $\mathrm{DC}-$ CIK cells gradually increased. 
Table 1. Expression rate of cell surface antigen in three groups $(\bar{x} \pm s, \%)$.

\begin{tabular}{|c|c|c|c|c|c|c|}
\hline & $\mathrm{CD}_{1 \mathrm{a}}$ & $\mathrm{CD}_{83}$ & $\mathrm{CD}_{86}$ & $\mathrm{CD}_{80}$ & $\mathrm{CD}_{40}$ & HLA-DR \\
\hline DC-CIK & $72.45 \pm 3.11$ & $75.16 \pm 2.24$ & $74.52 \pm 2.97$ & $77.15 \pm 2.77$ & $76.32 \pm 3.10$ & $80.26 \pm 3.45$ \\
\hline DC & $54.07 \pm 2.41$ & $52.32 \pm 2.57$ & $56.33 \pm 2.82$ & $58.06 \pm 2.43$ & $57.38 \pm 2.47$ & $60.49 \pm 3.18$ \\
\hline ClK & $55.36 \pm 2.54$ & $49.22 \pm 3.18$ & $56.13 \pm 2.84$ & $55.04 \pm 3.15$ & $59.21 \pm 2.77$ & $61.42 \pm 3.29$ \\
\hline $\mathrm{T}$ value & -7.153 & -8.204 & -7.317 & -8.036 & -8.377 & -8.251 \\
\hline$P$ value & $<0.01$ & $<0.01$ & $<0.01$ & $<0.01$ & $<0.01$ & $<0.01$ \\
\hline
\end{tabular}

Table 2. The cells percentage of $C D 3+, C D 3+C D 4+, C D 3+C D 8+$, $C D 3+C D 56+$ in three groups $(\bar{x} \pm s, \%)$.

\begin{tabular}{lllll}
\hline Group & CD3+ & CD3+CD4+ & CD3+CD8+ & CD3+CD56+ \\
\hline DC-CIK & $82.56 \pm 4.94$ & $28.45 \pm 4.17$ & $96.52 \pm 7.33$ & $85.39 \pm 6.59$ \\
\hline DC & $75.35 \pm 3.64$ & $36.54 \pm 3.69$ & $78.41 \pm 6.25$ & $60.53 \pm 6.13$ \\
\hline CIK & $77.47 \pm 3.24$ & $39.44 \pm 3.55$ & $75.57 \pm 6.74$ & $57.44 \pm 6.37$ \\
\hline T value & -8.254 & 29.583 & -69.681 & -62.512 \\
\hline P value & $<0.01$ & $<0.01$ & $<0.01$ & $<0.01$ \\
\hline
\end{tabular}

After the DC and CIK cells were co-cultured, the proportion of the double positive expression of $\mathrm{CD} 3+$ and $\mathrm{CD} 3+\mathrm{CD} 4+$, $\mathrm{CD} 3+\mathrm{CD} 8+, \mathrm{CD} 3+\mathrm{CD} 56+$ on $\mathrm{DC}-\mathrm{CIK}$ cells increased compared with DC and CIK cells, while the expression ratio of CD3+CD4+ cell subsets decreased compared with DC and CIK cells, the difference was significant statistical significance $(\mathrm{p}<0.01$, Table 2$)$, and the difference between the group of DC and CIK group was not statistically significant $(\mathrm{p}>0.05)$.

Table 3. Killing activity to gastric cancer cell SGC-7901 in different effector-target ratio in three groups.

\begin{tabular}{|c|c|c|c|c|c|c|c|c|c|c|}
\hline \multirow[t]{2}{*}{ Groups } & \multicolumn{10}{|c|}{ Effector-target ratio } \\
\hline & $2.5: 1$ & & $5: 1$ & & $10: 1$ & & $20: 1$ & & $40: 1$ & \\
\hline DC-CIK & $\begin{array}{l}20.35 \\
3.72\end{array}$ & \pm & $\begin{array}{l}33.21 \\
3.54\end{array}$ & \pm & $\begin{array}{l}45.19 \\
4.15\end{array}$ & \pm & $\begin{array}{l}67.43 \\
5.17\end{array}$ & \pm & $\begin{array}{l}89.52 \\
5.38\end{array}$ & \pm \\
\hline DC & $\begin{array}{l}15.32 \\
3.54\end{array}$ & \pm & $\begin{array}{l}23.18 \\
3.61\end{array}$ & \pm & $\begin{array}{l}36.22 \\
3.47\end{array}$ & \pm & $\begin{array}{l}56.44 \\
7.30\end{array}$ & \pm & $\begin{array}{l}77.43 \\
7.28\end{array}$ & \pm \\
\hline $\mathrm{CIK}$ & $\begin{array}{l}16.37 \\
4.16\end{array}$ & \pm & $\begin{array}{l}25.29 \\
4.03\end{array}$ & \pm & $\begin{array}{l}37.31 \\
3.52\end{array}$ & \pm & $\begin{array}{l}58.45 \\
7.26\end{array}$ & \pm & $\begin{array}{l}79.50 \\
6.74\end{array}$ & \pm \\
\hline $\mathrm{T}$ value & 1.635 & & 2.264 & & 3.417 & & 7.311 & & 9.253 & \\
\hline$P$ value & 0 & & 0 & & 0 & & 0 & & 0 & \\
\hline
\end{tabular}

\section{Killing activity to gastric cancer cell SGC-7901 in different effector-target ratio in three groups}

The cell killing activity of DC-CIK cells DC cells and CIK cells to SGC-7901 cell was measured by MTT assay, the results showed that: three effector cells all had high cytotoxic activity, and the killing activity was within the effective target range of 2.5: 1-40:1, which showed a positive correlation, just as that the greater ratio of effective target, the higher efficiency of killing activity. The killing activity of DC-CIK cell was strongest, which gradually increased with titers higher, the difference was statistically significant compared with DC and CIK group, $(\mathrm{p}$ value $=0.000$, Table 3$)$.

\section{Detection of cytokines in three groups}

Cell supernatants having cultured for fourteen days were collected of three groups, the levels of IL-12, IL-4, TNF- $\alpha$ and IFN- $\gamma$ were detected with the ELISA kit. We found that concentration of IL-12, TNF- $\alpha$ IFN- $\gamma$ secreted in three groups were higher and which were significantly increased in CIK group compared with DC and CIK group, the difference were statistically significant $(p=0.000)$, especially in the secretion of IFN- $\gamma$ was significantly increased $(p=0.000)$. While the concentrations of IL-4 were lower cells secreted by the cells in the three groups compared with secretion concentration of IL-12, TNF- $\alpha$ and IFN- $\gamma$, the differences were statistically significant ( $\mathrm{p}$ value $=0.000$, Table 4 ).

Table 4. The concentration of $I L-12, I L-4, T N F-\alpha$ and $I F N-\gamma$ in the cell culture supernatant of three groups $(\bar{x} \pm s, n g / l)$.

\begin{tabular}{lllll}
\hline Group & IL-12 & IL-4 & TNF- $\alpha$ & IFN-y \\
\hline DC-CIK & $107.25 \pm 15.37$ & $9.37 \pm 8.53$ & $457.46 \pm 90.55$ & $796.51 \pm 183.74$ \\
\hline DC & $35.28 \pm 17.49$ & $10.42 \pm 9.75$ & $225.42 \pm 78.19$ & $349.61 \pm 97.16$ \\
\hline CIK & $38.31 \pm 17.53$ & $11.51 \pm 10.32$ & $234.52 \pm 80.23$ & $375.64 \pm 95.22$ \\
\hline T value & 4.473 & 2.356 & 7.187 & 12.295 \\
\hline P value & 0 & 0 & 0 & 0 \\
\hline
\end{tabular}

\section{Discussions}

DC was first discovered in 1973 by Steinman, which could uptake, process and handle antigens. It can effectively stimulate the initial and secondary immune response effector of T cells, and secrete IL-12 as the I cytokine of helper T cell type at the same time, which can also induce $T$ cells and natural killer cells (natural killer, NK) to produce IFN- $\gamma$ and enhancing the cytotoxic activity of NK activation by expressing type II histocompatibility antigens (major histocompatibility complex, MHC- II ), co-stimulatory molecules, cell adhesion molecule-1 (intercellular cell adhesion molecule-1, ICAM-1) and lymphocyte function associated antigen-1, LFA-1) and other cell surface molecules in vitro and in vivo. which can effectively induce resting $\mathrm{T}$ cell proliferation, but also can promote cell cytotoxic $\mathrm{T}$ lymphocytes and helper $\mathrm{T}$ lymphocytes to generate and activate lymphocytes just as $\mathrm{CD} 3+\mathrm{CD} 8+\mathrm{T}$ and $\mathrm{CD} 3+\mathrm{CD} 4+\mathrm{T}$ to migrate to the tumor site, 
after that it would secrete IL-12 and TNF- $\alpha$, induce the production of IFN- $\gamma$ by $\mathrm{T}$ cell and NK cells, further to develop anti-tumor effect [7]. DC can also affect the differentiation and proliferation of $\mathrm{B}$ cell; it can play a role in activation on the humoral immune response.

However, the DC function of patients with cancer was often defective, resulting in immune function lower or immune tolerance in patients, which is closely related to the progression, metastasis and recurrence of tumor [8]. CIK was a type of heterogeneous cells having CD3+CD8+ and CD3+CD56+ typically labelled, while expressing the surface marker CD3+CD56+T cell and NK cell, which was first reported in 1991 by Wolf et al. in Stanford University in USA [9]. CD3+CD56+T cells are the main effector cells of CIK population cells, which have both powerful anti-tumor activity of T cell and MHC restriction, kill the tumor characteristics of NK cells. It can also secrete high levels of IL-12, IFN- $\gamma$, TNF$\alpha$ and other I cytokines of helper T cell type, to regulate the secretion body's other cytokines to achieve sensitivity of promoting CIK cytotoxicity on tumor cells, so as to restrain tumor and anti-tumor effects, which is an effective anti-tumor cells, and it can be induced to proliferate in vitro [10,11]. But it does not have the characteristics specifically recognize and kill tumor cells.

DC and CIK are two important cell for tumor immunotherapy, the former identified and presented antigens to induce the proliferation of CIK cell, at the same time which can promote the secretion of various cytokines to strengthen the anti-tumor effect; the latter can be directly or indirectly kill the tumor. To do this, the co-culture of DC and CIK can not only enhance the DC maturity, so as to play a stronger antigen commission ability, but also increases the cytotoxic effect of CIK cells, which will undoubtedly play a synergistic anti-tumor effect.

There are research reported that after co-cultured of DC and CIK cells from peripheral blood cell count of CIK was expansion fold at the fourteenth day, which was five times as that on the $7^{\text {th }} \mathrm{d}$. But our experimental results showed that the number of DC-CIK cells on amplification and surface antigen expression were twenty times more than that for the number of DC and CIK cells after cultured $14 \mathrm{~d}$, which indicated that DC can promote the proliferation of CIK cell in peripheral blood of human. The results are basically the same as Mortara et al. [12]. It affects cells of DC-CIK, DC and CIK cells in peripheral blood of gastric cancer patients though directly induce culture and co-culture for DC and CIK in vitro in the study.

The results of MTT test showed that the killing effect of DCCIK was more strong than that of DC and CIK cells in same target cell with the same effect-target ration $(\mathrm{p}=0.000)$. While with the effector-target ratio $(2.5: 1 \sim 40: 1)$ increasing, the killing effect of DC-CIK to target cell gradually enhanced $(p=0.000)$. So we can speculate that when the concentration of cells increased in three groups, killing effect to gastric cancer cell would increase. Which show that DC-CIK induced to culture in vitro had a powerful killing effect to gastric cancer, the activity to anti gastric cancer was increased more compared with DC and CIK cells, which was in line with the results about immune response of DC-CIK cells against nasopharyngeal carcinoma reported by Zhou in China, while it confirmed that DC-CIK cells have stronger activity against gastric cancer than DC and CIK cells. CIK was a type of heterogeneous cells and its anti-tumor effect was closely related with $\mathrm{CD} 3+\mathrm{CD} 8+, \mathrm{CD} 3+\mathrm{CD} 56+$ double positive cells and secretion of cytokines levels.

At the same time CIK cells had the advantage of antitumor activity of the $\mathrm{T}$ cells and the non-MHC restricted killing activity tumor of NK cells. The results of the detection to the DC-CIK, and DC and CIK cell subsets confirmed that DC-CIK generated more $\mathrm{CD} 3+\mathrm{CD} 8+$ and $\mathrm{CD} 3+\mathrm{CD} 56+$ than $\mathrm{DC}$ and CIK cell after culture in vitro. It means DC-CIK produce more cytotoxic lymphocytes.

The proportions of CD3+CD56+ in DC, CIK and DCIK cells were all more than $20 \%$, but the proportions of the helper $t$ lymphocytes CD3+CD4+ helper a lower than that before inducing, which showed that the inducible factor added in induced-culture in vitro was benefit to the propagation of $\mathrm{CD} 3+\mathrm{CD} 56+$ and CD3+CD8+ and in enhanced cytotoxicity of $\mathrm{CIK}$, as a result that improved its killing activity to gastric cancer cell. While the result also shows that the co-culture of autologous DC induced to culture in vitro can promote the proliferation of effector cells which has the CIK cytotoxic effector, and the increase the number of effector cells, so as to the CIK got a stronger activity killing activity to cancer.

DC and CIK cells were co-cultured, they both can respectively kill tumor cells by identifying the antigen, activating acquired immune system and playing their own cytotoxic activity and secreting cell factor, thus formed a highly efficient immune effect. On the one hand, it may be that CIK can kill tumor cells by exerting its own cytotoxicity, on the other hand, CIK and DC can identify and induce the secretion of IL-12 and IFN- $\gamma$ each other, further to activate the cytotoxic activity of $\mathrm{CD} 3+\mathrm{CD} 56+$ cells and $\mathrm{CD} 3+\mathrm{CD} 8+$ cells to inhibit tumor growth [12].

Therefore, we detected the cell factor in the supernatant of the three groups of cells, and found that the concentration of IL-12, TNF- $\alpha$ and IFN- $\gamma$ in the supernatant of DC-CIK group was significantly higher than that of $\mathrm{DC}$ and $\mathrm{C} 1 \mathrm{~K}$, while the concentration of IL- 4 was decreased $(p=0.000)$. When DC is activated by immature state, it will secrete a large number of IL-12, IL-12, which not only mediates the immune response of $\mathrm{T}$ cells, promotes the proliferation and actives of cytotoxic $\mathrm{T}$ cells, but also induces IFN- cells and stimulates NK cells and helpful $\mathrm{T}$ cells to secrete IFN- $\gamma$, improve the cytotoxic activity of NK cells [13].

Thus, it can be inferred that the killing effect to gastric cancer cells in the co-culture of DC and CIK cells plays a synergistic effect, DC and CIK were identified each other, and the expression of cytokines and surface molecules was changed, DC promotes the proliferation of CIK cells and the extend the time of release and increase production of IFN- $\gamma$ and TNF- $\alpha$ 
and by secreting IL-12 [14]. Further to enhance the resistance of the DC-CIK activity of gastric cancer $[15,16]$.

DC-CIK cells were showed having strong antitumor activity, which was directly or indirectly related to the number of $\mathrm{CD} 3+\mathrm{CD} 56+$ and $\mathrm{CD} 3+\mathrm{CD} 8+$ positive cells and the secretion of IL-12, IFN- $\gamma$, TNF- $\alpha$ and so on. IL-4 is a growth factor secreted by $\mathrm{T}$ cells, which can maintain the growth of helper $\mathrm{T}$ cells. As a kind of tumor immune modulator, the decrease of IL-4 secreted by DC-CIK may be one of the reasons for the non-proliferation of helpful $\mathrm{T}$ cells $\mathrm{CD} 3+\mathrm{CD} 4+$ in DC-CIK and IL-4 may not be involved in the anticancer effect of DCCIK.

We speculated that secreting a large number of cytokines and producing cytotoxic cells may be one of the important mechanisms of DC-CIK cells against gastric cancer.

The research preliminarily affirmed that the effect of DC-CIK gastric cancer cells was obviously higher than DC and CIK cells, it can be used as an immunotherapy method of resistance to gastric cancer, what's more it provides experimental and theoretical basis for application of DC-CIK in biological immunotherapy of gastric cancer.

\section{Acknowledgement}

China Postdoctoral Science Foundation (20100471770).

\section{References}

1. Bedognetti D, Wang E, Sertoli MR, Marincola FM. Gene expression profiling in vaccine therapy and immunotherapy for cancer. Expert Rev Vaccines 2010; 9: 555-565.

2. Di Nicola M, Zappasodi R, Carlo-Stella C, Mortarini R, Pupa SM, Magni M, Devizzi L, Matteucci P, Baldassari P, Ravagnani F, Cabras A, Anichini A, Gianni AM. Vaccination with autologous tumor-loaded dendritic cells induces clinical and immunologic responses in indolent Bcell lymphoma patients with relapsed and measurable disease: a pilot study. Blood 2009; 113: 18-27.

3. Bercovici N, Haicheur N, Massicard S, Vernel-Pauillac F, Adotevi O, Landais D, Gorin I, Robert C, Prince HM, Grob JJ, Leccia MT, Lesimple T, Wijdenes J, Bartholeyns J, Fridman WH, Salcedo M, Ferries E, Tartour E. Analvsis and characterization of antitumor T-cell response after administration of dendritic cells loaded with allogeneic tumor lysate to metastatic melanoma patients. J Immunother 2008; 31: 101-112.

4. Schmidt-Wolf IG, Lefterova P, Mehta BA, Fernandez LP, Huhn D, Blume KG, Weissman IL, Negrin RS. Phenotypic characterization and identification of effector cells involved in tumor cell recognition of cytokine-induced killer cells. Exp Hematol 1993; 21: 1673-1679.

5. Linn YC, Hui KM. Cytokine-induced killer cells: NK-like $\mathrm{T}$ cells with cytotolytic specificity against leukemia. Leuk Lymphoma 2003; 44: 1457-1462.

6. Sun JC, Pan K, Chen MS, Wang QJ, Wang H, Ma HQ, Li YQ, Liang XT, Li JJ, Zhao JJ, Chen YB, Pang XH, Liu
WL, Cao Y, Guan XY, Lian QZ, Xia JC. Comparative study on anti-tumor immune response of autologous cytokine induced killer (CIK) cells, dendritic cells CIK (DC-CIK) and semi allogeneic DC-CIK. Chin J Cancer 2010; 29: 641-648.

7. Tuyaerts S, Van Meirvenne S, Bonehill A, Heirman C, Corthals J, Waldmann H, Breckpot K, Thielemans K, Aerts JL. Expression of human GITRL on myeloid dendritic cells enhances their immunostimulatory function but does not abrogate the suppressive effect of CD4+CD25+ regulatory T cells. J Leukocyte Biol 2007; 82: 1-13.

8. Wongkajornsilp A, Somchitprasert T, Butraporn R, Wamanuttajinda V, Kasetsinsombat K, Huabprasert S, Maneechotesuwan K, Hongeng S. Human cytokineinduced killer cells specifically infiltrated and retarded the growth of the inoculated human cholangiocarcinoma cells in SCID mice. Cancer Invest 2009; 27: 140-148.

9. Negrin RS, Kiem HP, Schmidt-Wolf IG, Blume KG, Cleary ML. Use of a SCID mouse/human lymphoma nmdel to evaluate cytokine-induced killer cells with potent antitumor activity. J Exp Med 1991; 174: 139-149.

10. Sangiolo D, Mesiano G, Carnevale-Schianca F, Piacibello W, Aglietta M, Cignetti A. Cytokine induced killer cells as adoptive immunotherapy strategy to augment graft versus tumor after hematopoietic cell transplantation. Expert Opin Biol Ther 2009; 9: 831-840.

11. Niam M, Linn YC, Fook Chong S, Lim TJ, Chu S, Choong A, Yong HX, Suck G, Chan M, Koh M. Clinical scale expansion of cytokine-induced killer cells is feasible from healthy donors and patients with acute and chronic myeloid leukemia at various stages of therapy. Exp Hematol 2011; 39: 897-903.

12. Mortara L, Giuliani L, De Lerma Barbaro A, Accolla RS, Noonan DM. Experimental therapeutic approaches to adenocarcinoma: the potential of tumor cells engineered to express MHC class II molecules combined with naked DNA interleukin-12 gene transfer. Surg Oncol 2007; 16: 33-36.

13. Shi CC, Tjwa ET, Biesta PJ, Boonstra A, Xie Q, Janssen HL, Woltman AM. Hepatitis B virus suppresses the functional interaction between natural killer cells and plasmacytoid dendritic cells. J Viral Hepat 2012; 19: 26-33.

14. Sun TY, Yan W, Yang CM, Zhang LF, Tang HL, Chen Y, $\mathrm{Hu}$ HX, Wei X. Clinical study of dendritic cells vaccine enhanced the immuno competence of the postoperively patients with hepatocellular carcinoma. GMR 2015; 14: 16222-16232.

15. Linn YC, Hui KM. Cytokine-induced killer cells: NK-like $\mathrm{T}$ cells with cytotolytic specificity against leukemia. Leuk Lymphoma 2003; 44: 1457-1462.

16. Schmidt J, Eisold S, Buchler MW, Marten A. Dendritic cells reduce number and function of $\mathrm{CD} 4+\mathrm{CD} 25+$ cells in cytokine-induced killer cells derived from patients with pancreatic carcinoma. Cancer Immunol Immunother 2004; 53: 1018-1026. 
An experimental study on DC-CIK cells' immuno effects on killing gastric cancer cells in vitro

\section{*Correspondence to}

Xuan Wei

Department of General Surgery

Air Force General Hospital

Beijing

PR China 